\title{
Fasting and postprandial ileal function in adapted ileostomates and normal subjects
}

\author{
S D LADAS, P E T ISAACS, G M MURPHY, AND G E SLADEN \\ From the Gastroenterology Unit, Guy's Hospital, London
}

SUMmary The output of 11 established ileostomies was compared with ileal flow measured by intestinal perfusion in five normal volunteers when fasting and during the ileal passage of test meals containing different proportions of medium chain triglyceride and long chain triglyceride. Oroileal transit of the meal was the same in the two groups, but ileostomy output was less than ileal flow of normal persons both fasting $(16.3 \pm 10.9$ vs $62.4 \pm 24.7 \mathrm{ml} / \mathrm{h}, \mathrm{p}<0.001)$ and after the longchain triglyceride rich meal $(35.4 \pm 27.0 \mathrm{vs} 96 \cdot 1 \pm 20.2 \mathrm{ml} / \mathrm{h}, \mathrm{p}<0.001)$. After ingestion of the medium chain triglyceride rich meal, ileal flow failed to increase in normal subjects but in ileostomates the changes in flow after medium chain triglyceride and long chain triglyceride rich meals were not significantly different. The fasting ileostomy effluent composition differed from that of normal fasting ileal content in having a higher concentration of potassium $(8.0 \pm 2.9 \mathrm{vs}$ $4.7 \pm 0.6 \mathrm{mmol} / \mathrm{l}, \mathrm{p}<0 \cdot 04)$ and a higher osmolality $(353 \pm 63$ vs $287 \pm 5 \mathrm{mosm} / \mathrm{kg}, \mathrm{p}<0.05)$. Sodium concentration tended to be lower in ileostomy effluent, but in contrast to previous reports, ileostomy effluent was of consistently alkaline $\mathrm{pH}(7 \cdot 2 \pm 0 \cdot 3)$. These concentrations were not significantly altered by either type of meal. The long chain triglyceride rich meal increased the ileal flow of bile acids in both normal subjects and ileostomates, whereas the medium chain triglyceride rich meal increased bile acid flow in ileostomates but not in normal subjects, possibly reflecting a different amount of the bile acids in the ileum of the ileostomate. In the adapted ileostomate, the low volume and high potassium concentration of fasting effluent suggest that sodium and water absorption are continuously stimulated by chronic salt depletion.

After the creation of an ileostomy, a process of adaptation occurs, whereby the loss of water in the ileostomy effluent becomes less than the $1 \cdot 5-2 \cdot 01 / \mathrm{d}^{1}$ entering the colon in the intact subject. Volumes of the ileostomy effluent are variable in the immediate post-operative period ${ }^{2}{ }^{3}$ but in the ileostomy, established for at least 10 days, the volume is $0.4-0.6 \mathrm{Vd} .^{23}$

The physiological mechanisms underlying ileostomy adaptation are not known. Possibly increased absorption of salt and water is a response to a state of chronic salt depletion which is common in ileostomates. ${ }^{4-6}$ Such a response would be hormonally mediated and although plasma aldosterone concentrations are reputedly normal ${ }^{67}$ other salt retaining steroids such as 18 -hydroxycorticosterone ${ }^{8}$ could be playing a role. In addition, an increase in the transit time of the small intestinal contents could

Address for correspondence: Dr G E Sladen, Department of Gastroenterology, Guy's Hospital, St. Thomas' Street, London, SE1 9RT.

Received for publication 21 November 1985. reduce ileal flow by increasing the mucosal contact time and absorption of water and salt.

Current ideas of ileostomy function are based mainly on pooled 24 hour collections of the ileostomy effluent which may obscure differences in postprandial ileal flow caused by changes in intestinal motility, and absorption, although the more continuously acting response to chronic salt depletion $^{9}{ }^{10}$ would still be evident. Furthermore, there are problems of analysis of pooled ileostomy effluent which may continue to ferment in the bag or container, generating short chain fatty acids or other bacterial metabolites giving potentially inaccurate estimates of such parameters as $\mathrm{pH}$ and osmolality. We have, therefore, made a direct comparison of freshly sampled ileostomy output and flow in the intact ileum under fasting conditions and in response to the stimulus of two liquid meals, which we have shown to produce marked differences in ileal flow, gall bladder contraction and bile acid input into the colon. ${ }^{11}$ 
Methods

\section{SUBJECTS}

Five healthy normal subjects (age range 22-54 years, four men and one woman) and 11 ileostomates (age range 18-65 years, five men and six women), who had a colectomy for ulcerative colitis 2-12 years previously were studied. All were taking a normal diet and were not on any medication. The ileostomates had not had any ileum resected or any other abdominal surgery.

All subjects gave their consent after an oral and written explanation of the study which was approved by the Ethical Committee of Guy's Hospital and the Ileostomy Association of Great Britain.

Subjects were admitted to hospital for the two to three days of the study. On each day the subjects had fasted from midnight. On the first day the normal subjects and two of the ileostomates swallowed a weighted radio-opaque multilumen tube which was then allowed to pass down the intestine whilst they took normal meals. The progress of the tube was checked at intervals by fluoroscopy until the mercury bag was seen in the caecum. The aspiration point was located $15 \mathrm{~cm}$ cephalad to the bag and thereby positioned in the terminal ileum at the beginning of the perfusion on the second day. Fluoroscopy was repeated after the first perfusion and before and after the second perfusion to ensure that the bag had not moved. In the two ileostomates the aspiration port was situated at 240 and $275 \mathrm{~cm}$ from the incisors. Through the second lumen which opened at $25 \mathrm{~cm}$ proximal to the ileal aspiration site, a plasma like solution (Na 135, K 5, Cl 105, $\mathrm{HCO}_{3} 35 \mathrm{mmol} / \mathrm{l}$, osmolality $280 \mathrm{mosm} / \mathrm{kg}$ ) containing ${ }^{14} \mathrm{C}$-polyethylene glycol (PEG) $10 \mu \mathrm{Ci} / \mathrm{l}$ and PEG (4000d) $2 \mathrm{~g} / \mathrm{l}$ was perfused at $0.3 \mathrm{ml} / \mathrm{min}$ with a peristaltic pump (model 1203A, Harvard Instruments, South Natick, Ma, USA).

The distal ileal lumen was continuously aspirated by a syringe pump (Perfusor Mk IV, Braun AG, Melsungen) set at $0.3 \mathrm{ml} / \mathrm{min}$, discarding the samples from the first hour of the perfusion and thereafter collecting the aspirates in half hour aliquots. The position of the tube was confirmed fluoroscopically at the end of the study.

The ileostomates were not intubated but 30 minute collections of the ileostomy effluent were made over the five hour study period during which all subjects lay semisupine.

The perfusion of normal subjects was allowed to equilibrate for 60 minutes. All subjects then underwent a 60 minute collection period before ingesting one of two liquid semi-elemental meals randomly selected. The meals were a standard Lundh-type test meal prepared by the dietitians and a commercially available medium chain triglyceride rich meal (Trioosorbon, BDH Ltd, Poole, UK). Both meals had a volume of $300 \mathrm{ml}$ and contained $150 \mathrm{mg}$ phenol red as a non-absorbable marker and had an energy value of $1.7 \mathrm{MJ}$ (400 kcal), derived from fat $(36 \%)$ carbohydrate $(48 \%)$ and protein $(16 \%)$ but the fat was $80 \%$ medium-chain triglyceride (medium chain triglyceride) and $20 \%$ long chain triglyceride (long chain triglyceride) in one meal and 30:70 medium chain triglyceride:long chain triglyceride in the other. Thirty minute collections of ileostomy effluent or ileal aspirate were obtained for five hours after ingestion of the meal.

When the experiment was completed the subject ate and drank normally until midnight and on the next morning the study was repeated in an identical way except that the other meal of the pair was given. None of the subjects experienced any nausea or abdominal pain after either meal.

The oroileal transit time of the head of the meal was taken as the interval between the ingestion of the meal and the appearance in the ileal aspirate or ileostomy effluent of phenol red discolouration, which was readily visible in this alkaline environment. This parameter was used because the curves of phenol red concentration showed a very long disappearance phase, which was not amenable to mean transit time analysis. Phenol red appearance is thus only a measurement of the oroileal transit of the initial bolus of the liquid meal.

On completion of each 30 minute collection immediate measurements of $\mathrm{pH}$ and of osmolality (freezing point depression, Osmette, Precision Instruments Inc, Boston, USA) were made on the fresh uncentrifuged specimen to avoid changes due to bacterial fermentation. Very viscous ileostomy effluent samples were mixed with an equal volume of water. Duplicate $100 \mu$ l aliquots of the ileal aspirates were retained for scintillation counting and all samples were then stored at $-20^{\circ} \mathrm{C}$ for subsequent measurement of the concentrations of $\mathrm{Na}$ and $\mathrm{K}$ by flame photometry, of phenol red ${ }^{12}$ and of total 3 alpha-hydroxy bile acids. ${ }^{13}$ The ileal aspirates were counted in $10 \mathrm{ml} \mathrm{NE} 260$ scintillation cocktail (Nuclear Enterprises, Sighthill, Edinburgh) on a liquid scintillation counter (Rack-Beta 1214, LKBWallac, Finland). A colour quench correction curve was made using a series of ileal samples to which were added a fixed amount of ${ }^{14} \mathrm{C}-\mathrm{PEG}$ and increasing amounts of phenol red within the range observed in the samples. This method gave a coefficient of variation of $2 \%$ for repeated observations on the same sample and $4 \%$ for multiple samples from the same specimen. The ileal flow rate $\left(F_{i}\right)$ was calculated as follows: $F_{i}=F_{\text {in }}\left(P E G_{\text {in }}\right)\left(P E G_{\text {out }}\right)^{-1}$, where $F_{\text {in }}$ is the infusion rate $(0.3 \mathrm{ml} / \mathrm{min}), P G_{\text {in }}$ 
and $\mathrm{PEG}_{\text {out }}$ are the activities (in distintegrations per minute) for ${ }^{14} \mathrm{C}$ in the infusate and ileal aspirate. This formula assumes that there is complete mixing of the infusate with the ileal contents and that the small volume of the infusate is completely absorbed by the terminal ileum. The assumptions underlying these calculations are discussed by Levitt and Bond. ${ }^{14}$

\section{STATISTICAL ANALYSIS AND CALCULATIONS}

To compare the effect of each meal on the ileal flow, variability in the intestinal transit has been eliminated and the results were grouped so that the first half hour sample which contained the meal marker (phenol red) was regarded as the first postprandial sample (PI). The ileal flow rate as well as the ileal output of $\mathrm{Na}, \mathrm{K}$ and bile acids were calculated over a two hour period and the results expressed per hour. The results in the text and figures are expressed as mean $\pm 1 \mathrm{SD}$. Analysis of variance was used to compare the serial changes in the two groups studied (normals and ileostomates) ${ }^{15}$ and a paired $t$ test to compare the fasting and postprandial results within each group. Results which were not normally distributed were examined by Wilcoxon's signed rank test.

\section{Results}

The head of the medium chain triglyceride and the long chain triglyceride rich meals appeared at the ileostomy at an interval after ingestion similar to that observed at the ileum of normal subjects. (See Table 1). Both fasting and postprandial flow rates from ileostomies were less than the ileal flow rates observed in normal subjects $\left(\mathrm{F}_{3 \cdot 28}=11 \cdot 7, \mathrm{p}<0 \cdot 001\right.$ and $F_{3.28}=9.51, p<0.001$ respectively, Table 1). There was a significant increase in ileal flow $(p<0.01$, Fig. 1a) in normal subjects and in ileostomy flow after the long chain triglyceride rich meal $(p<0.03$, Fig. 1b). The effects of long chain triglyceride and medium chain triglyceride rich meals on the average increase in ileal flow were different in the normal subjects, the long chain triglyceride rich meal inducing a significantly greater increase in ileal flow than that induced by the medium chain triglyceride rich meal $(40.9 \pm 19$ vs $1.8 \pm 8.7 \mathrm{ml} / \mathrm{l}$ respectively, $t=3.08, v=4, p<0.02$ ) but the effect of the two meals on ileostomy output was the same $(19 \cdot 1 \pm 26 \cdot 4$ vs $14 \cdot 2 \pm 28 \cdot 1 \mathrm{ml} / \mathrm{h}$ respectively. $\mathrm{t}=1 \cdot 28$, $\mathrm{v}=10, \mathrm{p}=0 \cdot 1)$. Perfusion studies were carried out on only two ileostomates. They both took a long chain triglyceride rich meal and refused a second study. The volume of effluent and ileal flow estimated by ileal perfusion (Table 2) show a close correlation $(\mathrm{r}=0.81, \mathrm{p}<0 \cdot 001)$.

The concentrations of sodium in ileostomy effluent were more variable than those of ileal aspirates but the means were not significantly different. Potassium concentration (Fig. 2), however, was significantly higher in ileostomy both fasting and postprandially than in the corresponding ileal aspirate.

Because of the differences in volume flow the total ileal output of sodium (Table 1) was greater in the normal subjects than in ileostomates both in the fasting state $(\mathrm{p}<0.001)$ and postprandially $(p<0 \cdot 001)$. The higher potassium concentration and lower flow in ileostomates, however, resulted in no significant difference between the postprandial potassium outputs of the two groups $(p=0 \cdot 1)$.

Table 1 Transit of meals to ileum and ileal flow rates of water electrolytes and bile acids in ileostomates compared with normal subjects

\begin{tabular}{|c|c|c|c|c|c|c|c|c|c|c|}
\hline & & \multirow{2}{*}{$\begin{array}{l}\text { Transit } \\
\text { the meal } \\
\text { (mins) }\end{array}$} & \multicolumn{2}{|l|}{$\begin{array}{l}\text { Ileal Flow } \\
(\mathrm{ml} / \mathrm{h})\end{array}$} & \multicolumn{2}{|l|}{$\begin{array}{l}\text { Na outflow } \\
(\text { mmollh) }\end{array}$} & \multicolumn{2}{|l|}{$\begin{array}{l}\text { K outflow } \\
\text { (mmol/h) }\end{array}$} & \multicolumn{2}{|l|}{$\begin{array}{l}\text { Ba outflow } \\
\text { (mmollh) }\end{array}$} \\
\hline & & & Fast & Postprandial & Fast & Postprandial & Fast & Postprandial & Fast & Postprandial \\
\hline \multirow{3}{*}{$\begin{array}{r}\text { Ileostomy } \\
(n=11)\end{array}$} & MCT & $84 \cdot 6 \pm 35 \cdot 8$ & $12 \cdot 3 \pm 8 \cdot 5$ & $26 \cdot 6 \pm 25 \cdot 2$ & $1.09 \pm 0.61$ & $3 \cdot 28 \pm 3 \cdot 34$ & $0.09 \pm 0.07$ & $0 \cdot 23 \pm 0 \cdot 19$ & $0 \cdot 05 \pm 0.06$ & $0 \cdot 11 \pm 0 \cdot 11^{*}$ \\
\hline & LCT & $73 \cdot 6 \pm 39 \cdot 7$ & $16 \cdot 3 \pm 10 \cdot 9$ & $35 \cdot 4 \pm 27 \cdot 0$ & $1 \cdot 46 \pm 1 \cdot 18$ & $4 \cdot 45 \pm 3 \cdot 69$ & $0.09 \pm 0.08$ & $0 \cdot 33 \pm 0 \cdot 24$ & $0 \cdot 02 \pm 0 \cdot 01$ & $0 \cdot 12 \pm 0 \cdot 12^{*}$ \\
\hline & MCT & $78 \cdot 0 \pm 14 \cdot 7$ & $49 \cdot 6 \pm 6 \cdot 3$ & $51 \cdot 4 \pm 11 \cdot 5$ & $5 \cdot 48 \pm 1 \cdot 57$ & $6 \cdot 74 \pm 1.38$ & $0.23 \pm 0.09$ & $0 \cdot 34 \pm 0 \cdot 09$ & $0 \cdot 09 \pm 0 \cdot 08$ & $0 \cdot 09 \pm 0 \cdot 02$ \\
\hline $\begin{array}{l}\text { Normal } \\
\text { subjects } \\
(\mathrm{n}=5)\end{array}$ & LCT & $66 \cdot 0 \pm 12 \cdot 0$ & $62 \cdot 4 \pm 24 \cdot 7$ & $96 \cdot 1 \pm 20 \cdot 2$ & $8 \cdot 17 \pm 3 \cdot 32$ & $13 \cdot 16 \pm 3 \cdot 16$ & $0 \cdot 28 \pm 0 \cdot 11$ & $0 \cdot 52 \pm 0.13$ & $0.06 \pm 0.03$ & $0.44 \pm 0.69^{*}$ \\
\hline $\begin{array}{l}\text { Significance } \\
\text { (analysis of } \\
\text { variance) }\end{array}$ & & $\begin{array}{l}F_{3.28}=0.4 \\
p=0.7\end{array}$ & $\begin{array}{l}F_{3.28}=21.7 \\
p<0.001\end{array}$ & $\begin{array}{l}F_{3.28}=9.51 \\
p<0.001\end{array}$ & $\begin{array}{l}F_{3.28}=24 \cdot 8 \\
p<0.001\end{array}$ & $\begin{array}{l}F_{3.28}=10 \cdot 3 \\
p<0.001\end{array}$ & $\begin{array}{l}F_{3.28}=8.7 \\
p<0.001\end{array}$ & $\begin{array}{l}F_{3.28}=2.3 \\
p<0 \cdot 1\end{array}$ & & \\
\hline
\end{tabular}

${ }^{*} \mathrm{p}<0.05$ (paired $\mathrm{t}$-test, fasting compared with postprandial)

$M C T=$ medium chain triglyceride

LCT $=$ long chain triglyceride

BA $=$ bile acid 
Both fasting and postprandial ileal osmolalities (Fig. 3) were significantly higher in the ileostomates compared with the normal subjects after either the long chain triglyceride and medium chain triglyceride rich meals $(\mathrm{p}<0.05$ to $\mathrm{p}<0.001)$.

The $\mathrm{pH}$ of the ileostomy effluent was no different $(p<0 \cdot 1)$ from that observed in the normal ileum either fasting or postprandially after either type of meal.
The bile acid concentrations in the fasting ileostomy effluent were not significantly higher than in the normal ileal aspirate but rose significantly at one hour after both the long chain triglyceride rich meal $(1 \cdot 6 \pm 1 \cdot 2$ to $3.2 \pm 2.2 \mathrm{mmol} / \mathrm{l}, \mathrm{t}=2 \cdot 33, \mathrm{v}=10, \mathrm{p}<0.05)$ and the medium chain triglyceride rich meal $(2.5 \pm 2 \cdot 1$ to $5 \cdot 7 \pm 4.8 \mathrm{mmol} / \mathrm{l}, \quad \mathrm{t}=2.72, \quad \mathrm{v}=10$, $\mathrm{p}<0.02)$. After the long chain triglyceride and
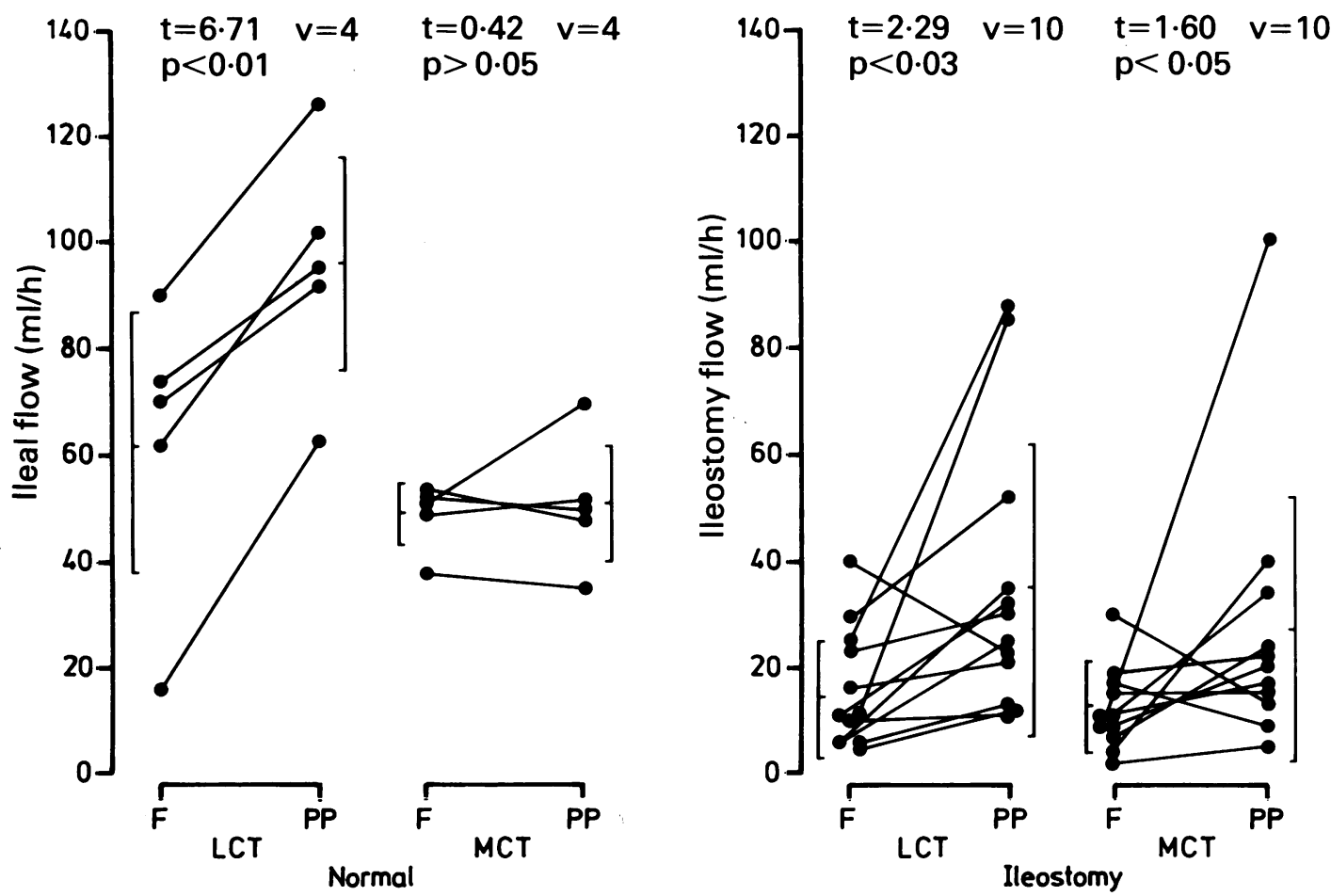

Fig. 1 Fasting $(F)$ and postprandial $(P P)$ flow rate (mean $+S D)$ in normal perfused ileum $(A)$ and of ileostomy effluent $(B)$ after ingestion of LCT- and MCT-rich meals.

Table 2 Ileal flow in two ileostomates measured both by flow of ejecta and by distal ileal perfusion (ml)

\begin{tabular}{ccccc}
\hline & $\begin{array}{l}\text { Subject } 1 \\
\text { Ejecta } \\
\text { volume }\end{array}$ & $\begin{array}{l}\text { Perfusion } \\
(240 \mathrm{~cm} \text { from incisors) }\end{array}$ & $\begin{array}{l}\text { Subject } 2 \\
\text { Ejecta } \\
\text { volume }\end{array}$ & $\begin{array}{l}\text { Perfusion } \\
(275 \mathrm{~cm} \text { from incisors) }\end{array}$ \\
\hline$-1 \cdot 0-0$ & $2 \cdot 0$ & $6 \cdot 8$ & $6 \cdot 0$ & $12 \cdot 4$ \\
$0-0 \cdot 5$ & $3 \cdot 0$ & $12 \cdot 0$ & $7 \cdot 0$ & $34 \cdot 8^{*}$ \\
$0 \cdot 5-1 \cdot 0$ & $52 \cdot 0$ & $76 \cdot 0^{*}$ & $70 \cdot 0^{*}$ & $60 \cdot 0$ \\
$1 \cdot 0-1 \cdot 5$ & $56 \cdot 0^{*}$ & $64 \cdot 6$ & $10 \cdot 0$ & $48 \cdot 8$ \\
$1 \cdot 5-2 \cdot 0$ & $34 \cdot 0$ & $47 \cdot 4$ & $40 \cdot 0$ & $11 \cdot 6$ \\
$2 \cdot 0-2 \cdot 5$ & $20 \cdot 0$ & $13 \cdot 2$ & $18 \cdot 0$ & $12 \cdot 0$ \\
$2 \cdot 3-3 \cdot 0$ & $15 \cdot 0$ & $11 \cdot 4$ & $6 \cdot 0$ & $14 \cdot 4$ \\
$3 \cdot 0-3 \cdot 5$ & $10 \cdot 0$ & $8 \cdot 8$ & $4 \cdot 0$ & $16 \cdot 2$ \\
$3 \cdot 5-4 \cdot 0$ & $5 \cdot 0$ & $5 \cdot 0$ & $20 \cdot 0$ & \\
\hline
\end{tabular}

*Indicates the first appearance of phenol red. 


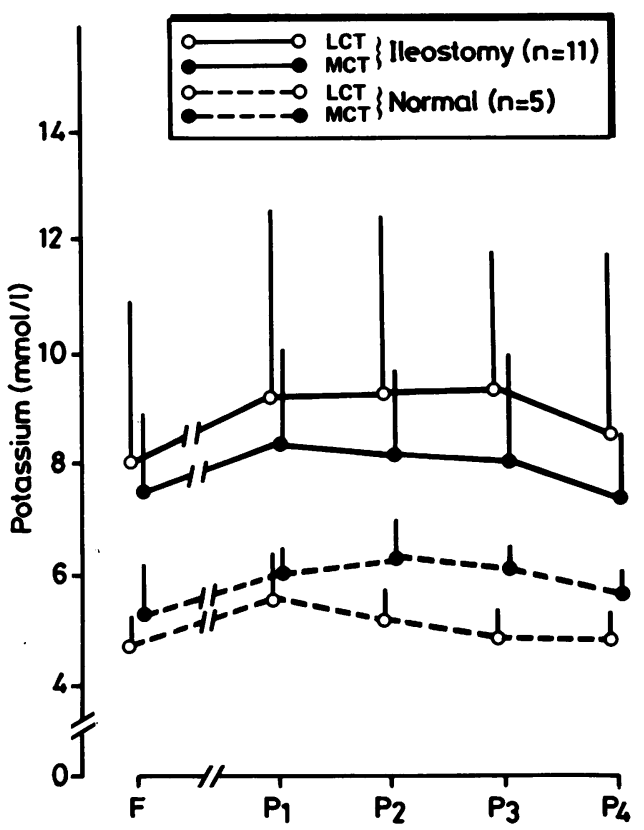

Fig. 2 Potassium concentration (mean $+S D$ ) in ileostomy effluent and ileal lumen fasting $(F)$ and in consecutive half hour periods (Pl to P4) after the appearance of phenol red in the ileal aspirate or ileostomy effluent. There were significant differences between the two groups both after the LCT (F: $p<0.04, P_{1}: p<0.04, P_{2}: p<0.03, P_{3}: p<0.02, P_{4}$ : $p<0.03)$ and the MCT meals (F: $p<0.01, P_{1}: p<0.03, P_{2}$ : $\left.p<0.05, P_{3}: p<0.05, P_{4}: p<0.02\right)$.

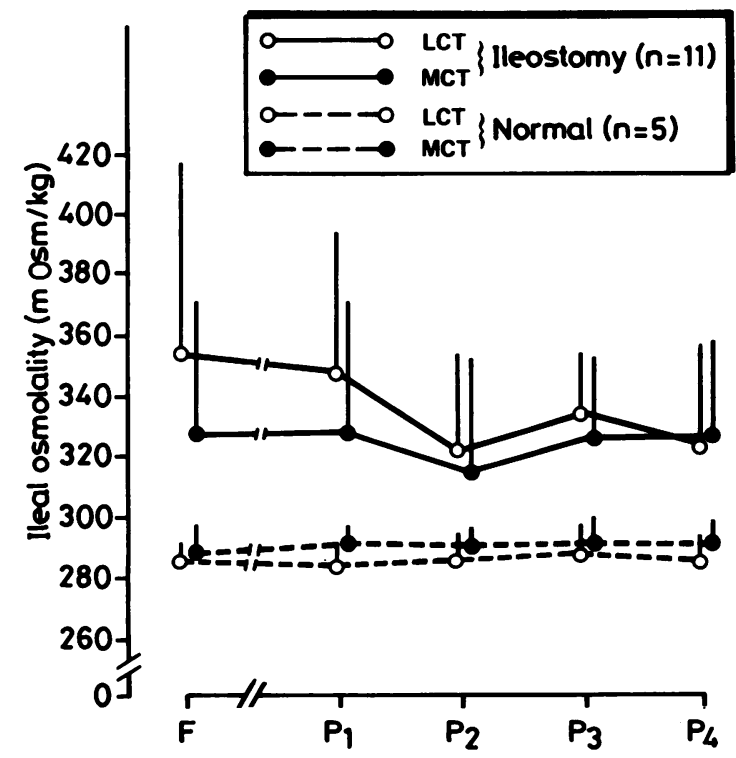

Fig. 3 Osmolality of ileal lumen and ileostomy effluent (mean $\pm S D)$ as in Figure 2. medium chain triglyceride rich meals in normal subjects, ileal bile acid concentrations were unchanged $(1.2 \pm 0.6$ to $6.7 \pm 11.7 \mathrm{mmol} / \mathrm{l}, \mathrm{t}=0.93$, $\mathrm{v}=4, \mathrm{p}=0.2$ and $(1.6 \pm 1.3$ to $0.5 \pm 0.3 \mathrm{mmol} / \mathrm{l}$, $\mathrm{t}=0.95, \mathrm{v}=4, \mathrm{p}=0.2$ respectively).

The ileal bile acid output (Table 1) was significantly increased in the postprandial period compared with the fasting period only following ingestion of the long chain triglyceride rich meal. In contrast with this in the ileostomates, the mean postprandial bile acid output was increased slightly above the fasting output by both types of meal stimulus $(\mathrm{p}<0 \cdot 05)$.

\section{Discussion}

Although it is generally thought that the total daily flow through the ileum is more than the amount discharged by a chronically established ileostomy, ${ }^{16}$ the present study is the first to compare freshly passed ileostomy effluent with normal flow under fasting conditions and in response to liquid test meals.

In the fasting state, we found the normal ileal flow to be about $60 \mathrm{ml} / \mathrm{h}$. Although the presence of an intestinal tube will delay gastric emptying and speed intestinal transit, ${ }^{17}$ the effects of intestinal intubation on fasting ileal flow are not known. Although it would have been desirable to carry out perfusion studies on all the ileostomates, we were able to do this on only two such subjects and found that the calculated flow rates were closely correlated to those obtained by collection of effluent.

The ionic composition of the ileostomy effluent differs from that of normal ileal fluid in having significantly greater concentration of potassium. Increased ileal fluid potassium concentration is seen in response to circulating mineralocorticoids ${ }^{18}$ and although the ileostomates studied were apparently healthy, a state of chronic sodium depletion exists in many of these individuals ${ }^{679}$ and increased circulating salt retaining mineralocorticoids may be responsible for the reduction of luminal flow by increased ileal sodium absorption. This stimulation of electrogenic sodium absorption increases transmucosal potential difference, which thereby enhances plasma to lumen diffusion of potassium. ${ }^{19}$ Despite presumably maximal ileal conservation of sodium, the well adapted fasting ileostomate must still lose sodium at the rate of $1 \mathrm{mmol} / \mathrm{h}$ when fasting and about 3 or $4 \mathrm{mmol} / \mathrm{h}$ in the postprandial period. This would lead to an obligatory loss of $24 \mathrm{mmol}$ of sodium per day from an ileostomy even whilst fasting absolutely and at least double this amount if three meals were to be consumed within a 24 hour period. 
Although the concentration of sodium in the ileostomy effluent was not significantly different from that in normal ileal fluid, the osmolality was consistently higher in ileostomy effluent, probably because of the presence of a greater bacterial flora ${ }^{20}$ in the established ileostomy which would generate metabolites such as short chain fatty acids. Although the osmolality of ileostomy effluent was higher than that of normal ileal fluid, the $\mathrm{pH}$ was, however, very similar. Because the osmolality and $\mathrm{pH}$ measurements were made immediately on freshly collected specimens from short collection periods an artificially low $\mathrm{pH}$ due to prolonged bacterial fermentation was obviated. Indeed, 24 hour pooled collections of ileostomy effluent have a relatively low $\mathrm{pH}^{21}$

The transit time of the head of the liquid meal was similar in ileostomates and normal subjects although transit of solid meals might have been a more discriminatory test. Evidence has been produced that nutrients especially fat in the ileum may inhibit jejunal motility ${ }^{22}$ and delay small bowel transit, ${ }^{23}$ but whether this occurs with both medium chain triglyceride and long chain triglyceride rich meals cannot be stated without measurement of mean transit time accurately by an alternative method. It is difficult, however, to apply to ileostomates the best methodology used in measuring intact small bowel transit. Breath hydrogen profiles after meals would not be comparable because in normal subjects they indicate mouth to caecum transit time while in ileostomates a rise in breath hydrogen would indicate contact of the substrate with the ileal flora.

Although in these studies the transit of the long chain triglyceride rich meals and medium chain triglyceride rich meals were similar, there were differences in ileal flow and bile acid output. The medium chain triglyceride rich meal did not increase ileal flow rate in normal subjects, whereas the long chain triglyceride rich meal did. In the ileostomates, changes in ileal flow after meals were more variable and there was no difference in the effect of medium chain triglyceride and long chain triglyceride rich meals. Similar effects on bile acid output were observed. Long chain triglyceride and medium chain triglyceride rich meals increased bile acid output in ileostomy effluent whereas only the long chain triglyceride rich meal increased bile acid flow from ileum to colon in normal subjects. It has been observed by others that the ileal excretion of bile acids correlates well with ileal flow in normal subjects and ileostomates and that bile acid feeding increases ileostomy flow. ${ }^{24}$ The different effects of the meals in the ileostomates compared with the normal subjects in the present study are intriguing. We have shown, in normal subjects, that medium chain triglyceride rich meals do not stimulate bile acid flow into the jejunum whereas long chain triglyceride rich meals do. ${ }^{10}$ This has not been studied in ileostomates but if it may be assumed that the gall bladder of the ileostomate responds in the normal way, then our observation that medium chain triglyceride rich meals increase ileostomy bile acid output suggests that in comparison with normal subjects, in the fasting ileostomate a greater proportion of the bile acid pool resides in the ileal lumen.

Although gross adaptations of small bowel function in the ileostomate have long been recognised, ${ }^{24} 25$ further examination of gut function of ileostomates under fasting conditions and in response to different meal stimuli may help differentiate the mechanisms underlying these adaptive responses.

A preliminary report of this study was presented at the BSG meeting of April 1984 (Gut, 1984; 25: A547. The study was supported by a Wellcome Trust Foundation Fellowship held by Dr Ladas and we would like to express our appreciation to our volunteers and the co-operation of the Ileostomy Association of Great Britain, to Miss Cathy Weeks for typing the manuscript and to $\mathrm{Mr}$ Younus Qureshi BSc for invaluable technical assistance.

\section{References}

1 Phillips SF, Giller J. The contribution of the colon to electrolyte and water conservation in man. J Lab Clin Med 1973; 81: 733-46.

2 Smiddy FG, Gregory SD, Goligher JC. Faecal loss of fluid, electrolytes and nitrogen in colitis before and after ileostomy. Lancet 1960; 1: 14-9.

3 Kanaghinis T, Lubran M, Coghill NF. The composition of ileostomy fluid. Gut 1963; 4: 322-38.

4 Clarke AM, Chirnside A, Hill GL, Pope G, Stewart MK. Chronic dehydration and sodium depletion in patients with established ileostomies. Lancet 1967; 2: 740-3.

5 Hill GL, Coligher JC, Smith AH, Mair WSJ. Longterm changes in total body water, total body exchangeable sodium and total body potassium before and after ileostomy. Br J Surg 1975; 62: 524-7.

6 Turnberg LA, Morris AI, Hawker PC, Herman KJ, Shields RA, Horth CE. Intracellular electrolyte depletion in patients with ileostomies. Gut 1978; 19: 563-8.

7 Isaacs PET, Horth CE, Turnberg LA. The electrical potential difference across human ileostomy mucosa. Gastroenterology 1976; 70: 52-8.

8 Sowers JR, Martin VI, Beck FWL. Effects of dietary sodium circadian rhythm and physiological responses of 18-hydroxycorticosterone. Clin Sci 1983; 64: 295-301.

9 Clarke AM, Hill GL, Macbeth WAAG. Intestinal adaptation to salt depletion in a patient with an ileostomy. Gastroenterology 1973; 81: 733-46. 
10 Moss S, Gordon D, Forsling ML, Peart WS, James VHT, Roddis SA. Water and electrolyte composition of urine and ileal fluid and its relationship to renin and aldosterone during dietary sodium deprivation in patients with ileostomies. Clin Sci 1981; 61: 407-15.

11 Ladas SD, Isaacs PET, Murphy GM, Sladen GE. Comparison of the effects of medium and long chain triglyceride containing liquid meals on gallbladder and small intestinal function in normal man. Gut 1984; 25: 405-11.

12 Schedl HP, Clifton JA. Small intestinal absorption of steroids. Gastroenterology 1961; 41: 491-9.

13 Talalay P. Enzymatic analysis of steroid hormones. In: Glick D, ed. Methods of biochemical analysis. Vol 8. New York: Interscience Publishers, 1960; 119-43.

14 Levitt MD, Bond J. Use of the constant perfusion technique in the non-steady state. Gastroenterology 1977; 73: 1450-4.

15 Winer BJ. Statistical principles in experimental design. Tokyo: McGraw-Hill, Kogakusha, 1971.

16 Binder $\mathrm{HJ}$. Absorption and secretion of water and electrolyte by small and large intestine. In: Sleisenger MH, Fordtran JS, eds. Gastrointestinal disease. Eastbourne: Saunders, 1982.

17 Read NW, Al Janabi MN, Bates TF, Barbara DC. Effect of gastro intestinal intubation on the passage of a solid meal through the stomach and small intestine in humans. Gastroenterology 1983; 84: 1568-73.

18 Levitan R, Goulston K. Water and electrolyte content of human ileostomy fluid after aldosterone administration. Gastroenterology 1967; 52: 510-2.

19 Turnberg LA. Potassium transport in the human small bowel. Gut 1971; 12: 811-8.

20 Gorbach SL, Nahas L, Weinstein L. Studies of intestinal microflora. IV The microflora of ileostomy effluent; a unique microbial ecology. Gastroenterology 1967; 53: 874-80.

21 Kramer P, Kearney MM, Ingelfinger FJ. The effect of specific food and water loading on the ileal excreta of ileostomized human subjects. Gastroenterology 1962; 42: $535-45$

22 Spiller RC, Trotman IF, Higgins BF, et al. The ileal brake-inhibition of jejunal motility after fat perfusion in man. Gut 1984; 25: 365-74.

23 MacFarlane A, Kinsman R, Read NW, Bloom SR. The presence of food in the ileum delays small bowel transit and gastric emptying. Gastroenterology 1983; 84: 1407.

24 Miettinen TA, Peltokallio P. Bile salt, fat, water and vitamin $\mathrm{B}_{12}$ excretion after ileostomy. Scand J Gastroenterol 1971; 6: 543-52.

25 Wright HK, Cleveland JC, Tilson MD, Herskovic T, Morphology and absorptive capacity of the ileum after ileostomy in man. Am J Surg 1969; 117: 242-5. 